\title{
A probable oligochaete from an Early Triassic Lagerstätte of the southern Cis-Urals and its evolutionary implications
}

\author{
Dmitry E. Shcherbakov, Tarmo Timm, Alexander B. Tzetlin, Olev Vinn, and Andrey Y. Zhuravlev \\ Acta Palaeontologica Polonica 65 (2), 2020: 219-233 doi:https://doi.org/10.4202/app.00704.2019
}

Oligochaetes, despite their important role in terrestrial ecosystems and a tremendous biomass, are extremely rare fossils. The palaeontological record of these worms is restricted to some cocoons, presumable trace fossils and a few body fossils the most convincing of which are discovered in Mesozoic and Cenozoic strata. The Olenekian (Lower Triassic) siliciclastic lacustrine Petropavlovka Lagerstätte of the southern Cis-Urals yields a number of extraordinary freshwater fossils including an annelid. The segmented body with a secondary annulation of this fossil, a subtriangular prostomium, a relatively thick layered body wall and, possibly, the presence of a genital region point to its oligochaete affinities. Other fossil worms which have been ascribed to clitellates are reviewed and, with a tentative exception of two Pennsylvanian finds, affinities of any pre-Mesozoic forms to clitellate annelids are rejected. The new fossil worm allows tracing of a persuasive oligochaete record to the lowermost Mesozoic and confirms a plausibility of the origin of this annelid group in freshwater conditions.

Key words: Annelida, Clitellata, Oligochaeta, Mesozoic, Lagerstätte, Russia.

Dmitry E. Shcherbakov [dshh@ @arod.ru], Borissiak Palaeontological Institute, Russian Academy of Sciences, Profsoyuznaya St 123, Moscow 117647, Russia.

Tarmo Timm [tarmo.timm@emu.ee], Centre for Limnology, Estonian University of Life Sciences, 61117, Rannu, Tartumaa, Estonia. Alexander B. Tzetlin [atzetlin@gmail.com

], Department of Invertebrate Zoology, Faculty of Biology, Lomonosov Moscow State University, Leninskie Gory 1(12), Moscow 119234, Russia. Olev Vinn [olev.vinn@ut.ee ], Institute of Ecology and Earth Sciences, University of Tartu, Ravila 14A, 50411, Tartu, Estonia. Andrey Y. Zhuravlev [ayzhur@mail.ru] (corresponding author), Department of Biological Evolution, Faculty of Biology, Lomonosov Moscow State University, Leninskie Gory 1(12), Moscow 119234, Russia.

This is an open-access article distributed under the terms of the Creative Commons 
Attribution License (for details please see creativecommons.org), which permits unrestricted use, distribution, and reproduction in any medium, provided the original author and source are credited.

\footnotetext{
FoF Full text $(930.1 \mathrm{kB})$ ।

Pof Supplementary file $(3.224 .9 \mathrm{kB})$
} 